\title{
Face to Face Counseling is Associated with Higher Exclusive Breast Feeding Rates at Six Weeks Compared to Audio-Visual Aids: A Randomized Controlled Trial
}

\section{Kanchan Sharma, Vinod Sharma and Pradeep Kumar Sharma*}

Senior Consultant SPS Apollo Hospitals, Ludhiana, India

*Corresponding author: Pradeep Kumar Sharma, Senior Consultant SPS Apollo Hospitals, Ludhiana, Tel: 09417938224; E-mail: psaiims@yahoo.co.in Rec date: Feb 28, 2014, Acc date: April 24, 2014; Pub date: April 26, 2014

Copyright: @ 2014 Sharma K, et al. This is an open-access article distributed under the terms of the Creative Commons Attribution License, which permits unrestricted use, distribution, and reproduction in any medium, provided the original author and source are credited.

\begin{abstract}
Background: Exclusive breast feeding rates are low in many countries including India despite its innumerable benefits. Counseling of mothers and use of audio-visual aids are among the strategies to promote exclusive breast feeding.
\end{abstract}

Objective: To study the efficacy of face-to-face counseling and using audio-visual aids on exclusive breast feeding rates at six weeks postnatal age.

Design: Randomized controlled trial

Setting: Tertiary care neonatal unit

Study period: January 2009 to June 2010

Subjects and methods: We randomized mothers with singleton births at gestation $\geq 36$ weeks into three groups: face-to-face counseling, video demonstration of a film on breast feeding and standard care. The infants were followed up at six weeks for evaluation of exclusive breast feeding.

Results: There were 1411 mothers randomized of whom $629(44.6 \%)$ followed up at six weeks. Face-to-face counseling was associated with a significant increase in exclusive breast feeding rates at six weeks, 271/326 $(83.1 \%)$ versus $97 / 135(71.8 \%)$; adjusted odds ratio $1.87(95 \% \mathrm{Cl} 1.15-3.04 ; \mathrm{p}=0.01)$. There was no effect of video demonstration $117 / 168(69.6 \%)$ on the same, adjusted odds ratio $0.93(95 \% \mathrm{Cl} 0.55-1.56 ; \mathrm{p}=0.67)$. The infants in the face-to-face counseling group required less hospitalization during the first six weeks of life $16 / 326(4.9 \%)$ than in the control group $15 / 135(11.1 \%)$; odds ratio $0.41(95 \% \mathrm{Cl} 0.20-0.86 ; p=0.02)$. There was no effect of video demonstration $10 / 168(6.0 \%)$, odds ratio $0.71(95 \% \mathrm{Cl} 0.47-1.08 ; \mathrm{p}=0.11)$.

Conclusions: Face-to-face counseling of mothers was associated with increased rates of exclusive breast feeding and decreased need for hospitalization of infants during the first six weeks of life. There is no effect of video demonstration of a film on breast feeding on the same.

Keywords: Face to face counseling; Exclusive breast feeding; Video counseling

\section{Introduction}

The World Health Organization recommends exclusive breast feeding for the first six months of life, continuing to two years or beyond with the addition of complementary foods at about 6 months of age [1]. Benefits of exclusive breastfeeding include decreased incidence of respiratory infections, diarrhea, asthma and allergic disorders [2]. There occurs a stronger emotional bonding between the mother and the infant [3]. Various studies show higher intelligence quotient in exclusively breast fed infants as compared to non-breast fed infants. The promotion of breastfeeding has been established as a global public health issue. Despite this global agenda, breastfeeding initiation and duration remains low. The reasons include lack of adequate support to the breastfeeding mother, lack of breast feeding counseling antenatally and postnatally, traditional practices of giving prelacteal feeds, working mothers, lack of awareness among mothers and other family members about benefits of exclusive breast feeding. At many places there is shortage of staff for promotion of exclusive breast feeding through individual counseling of mothers. Using audiovisual aids to increase exclusive breast feeding rates may be a feasible alternative in such situations. This may also be extended to the use of media like television for widespread promotion of exclusive breastfeeding.

We aimed to compare the efficacy of two different modes of breast feeding promotion after delivery; face-to-face counseling and video demonstration of a film on breast feeding versus standard care on exclusive breast feeding rates at six weeks postnatal age. 


\section{Subjects and Methods}

It was a randomized controlled trial conducted at Deen Dayal Upadhaya Hospital (DDUH), New Delhi from January 2009 to June 2010. All mothers who delivered singleton babies at $\geq 36$ weeks gestational age were eligible for the study. Exclusion criteria were multiple pregnancy, sick mother who is unable to communicate, major congenital malformation, babies admitted in neonatal intensive care unit, HIV positive mothers, mother on chemotherapy/planned for chemotherapy. Infant was labeled as exclusively breast fed if he/she had received only breast milk from his/her mother and no other liquids or solids with the exception of drops or syrups consisting of vitamins, mineral supplements or medicines since the time of counseling. Nuclear family was defined as a pair of adults with their children while joint family composed of parents, their children, and the children's spouses and offspring in one household. Parental education was based on the number of years of education.

\section{Sample size}

We did a pilot study on 100 babies to see the baseline exclusive breast feeding rates at six weeks which was $60 \%$. We hypothesised a $10 \%$ absolute increase in exclusive breast feeding rates with breast feeding counseling of mothers or use of audiovisual aids. Using alpha $=0.05$ and power $=80 \%$ our sample size was 1128 . Taking into account the attrition of $20 \%$ we enrolled 1411 mothers.

\section{Ethics and consent}

Ethical clearance was obtained from the institutional ethics committee of DDUH. Consent was taken from the mothers before enrolment.

\section{Randomization and blinding}

It was a randomized controlled trial. Blinding of the participants and the investigator was not possible due to the nature of the interventions, but the statistical analysis was done by the persons blinded to the codes. Random numbers were obtained from a computer generated table. Mothers were grouped into three groups: counseling group, video group and control group. The codes were kept in sealed opaque envelopes which were opened only after enrolment.

\section{Methods}

The principal investigator visited the postnatal wards daily except on holidays and sought consent from the eligible mothers who had delivered within the previous 24 hours. The mothers in the counseling group received face-to-face breast feeding counseling by a doctor who was trained for breast feeding counseling by the Breast Feeding Promotion Network of India (BPNI). Counseling was done in Hindi language which is understood and spoken by most of the people in the area where the hospital is localized. The duration of counseling was around 30 minutes. It included the anatomy of the breast, physiology of lactation, positioning, attachment, benefits of exclusive breast feeding and the solutions to handle the problems faced during breast feeding. It also included the hands-on breast feeding assistance. The mothers in the video group were shown a film in Hindi on breast feeding. The film was developed by the BPNI and is approximately of 30 minutes duration. It included the benefits of breast feeding and provided practical advice on breast feeding. The counseling and video demonstration was done in a separate room to prevent contamination and spillage effect to other mothers. The mothers in the control group received standard care which included routine advice for breast feeding by a nurse or a doctor.

The follow up was done at 6 weeks \pm 2 weeks in the follow up clinic for assessment of exclusive breast feeding rates, anthropometry and morbidity. The records were entered in a predesigned proforma. The family was provided with a written document mentioning the venue and time of visit. Those who did not turn up were reminded with telephone calls.

\section{Statistical Analysis}

It was done using SPSS for windows version 12 software. Demographic data were compared by analysis of variance for normally distributed variables, by Kruskal-Wallis test for skewed distributions and $\chi^{2}$ test for binomial variables. The rates of excusive breastfeeding at six weeks postnatal age were compared using $\chi^{2}$ test. Logistic regression was used with exclusive breast feeding at six weeks as the dependent variable.

\section{Results}

There were 1411 mothers enrolled of whom 511 were in the face-toface breastfeeding counseling group, 453 in the video group and 447 in the control group (Figure 1). Gestation, birth weight, gender, maternal age and cesarean rates were similar in the three groups while the parental education was higher in the face to face counseling group (Table 1). The video demonstration group had more antenatal checkups. The follow up rate at 6 weeks postnatal age was 326/511 (63.8\%) in the face-to-face counseling group, $168 / 453(37.1 \%)$ in video group and $135 / 447(30.2 \%)$ in the control group; $p=0.00$. The infants who followed up were compared with those who did not turn for follow up. There was no difference in gender, mode of delivery and the type of family. Those parents who turned up for follow up were more educated, professionals and had higher income than those who did not follow up. The exclusive breastfeeding rates at six weeks postnatal age were $271 / 326(83.1 \%)$ in the face-to-face breastfeeding counseling group, $117 / 168(69.6 \%)$ in the video group and $97 / 135(71.8 \%)$ in the control group; $\mathrm{p}=0.001$.

The exclusive breastfeeding rates were 360/454 (79.3\%) when mother or father were the decision makers in the family while $120 / 168$ (71.4\%) when grandparents were the decision makers; $\mathrm{p}=0.04$. Similarly, the exclusive breast feeding rates were higher in nuclear families 73/77 (94.8\%) than in joint families 410/549 (74.7\%); $\mathrm{p}=0.00$. After adjusting for the type of family, decision maker in the family, education, profession, income and antenatal check-ups, face-to-face counseling was associated with a significant increase in exclusive breast feeding rates at six weeks; adjusted odds ratio 1.87 (95\% CI $1.15-3.04 ; \mathrm{p}=0.01)$. There was no effect of video demonstration on the same; adjusted odds ratio 0.93 (95\% CI 0.55-1.56; $\mathrm{p}=0.67$ ).

The infants in the face-to-face counseling group required less hospitalization during the first six weeks of life $16 / 326(4.9 \%)$ than in the control group 15/135 (11.1\%); odds ratio 0.41 (95\% CI $0.20-0.86$; $\mathrm{p}=0.02)$. There was no effect of video demonstration $10 / 168(6.0 \%)$, odds ratio 0.71 (95\% CI 0.47-1.08; $\mathrm{p}=0.11$ ).

There was no difference in weight and head circumference at six weeks among the three groups (Table 2). 
Citation: Sharma K, Sharma V, Sharma KP (2014) Face to Face Counseling is Associated with Higher Exclusive Breast Feeding Rates at Six

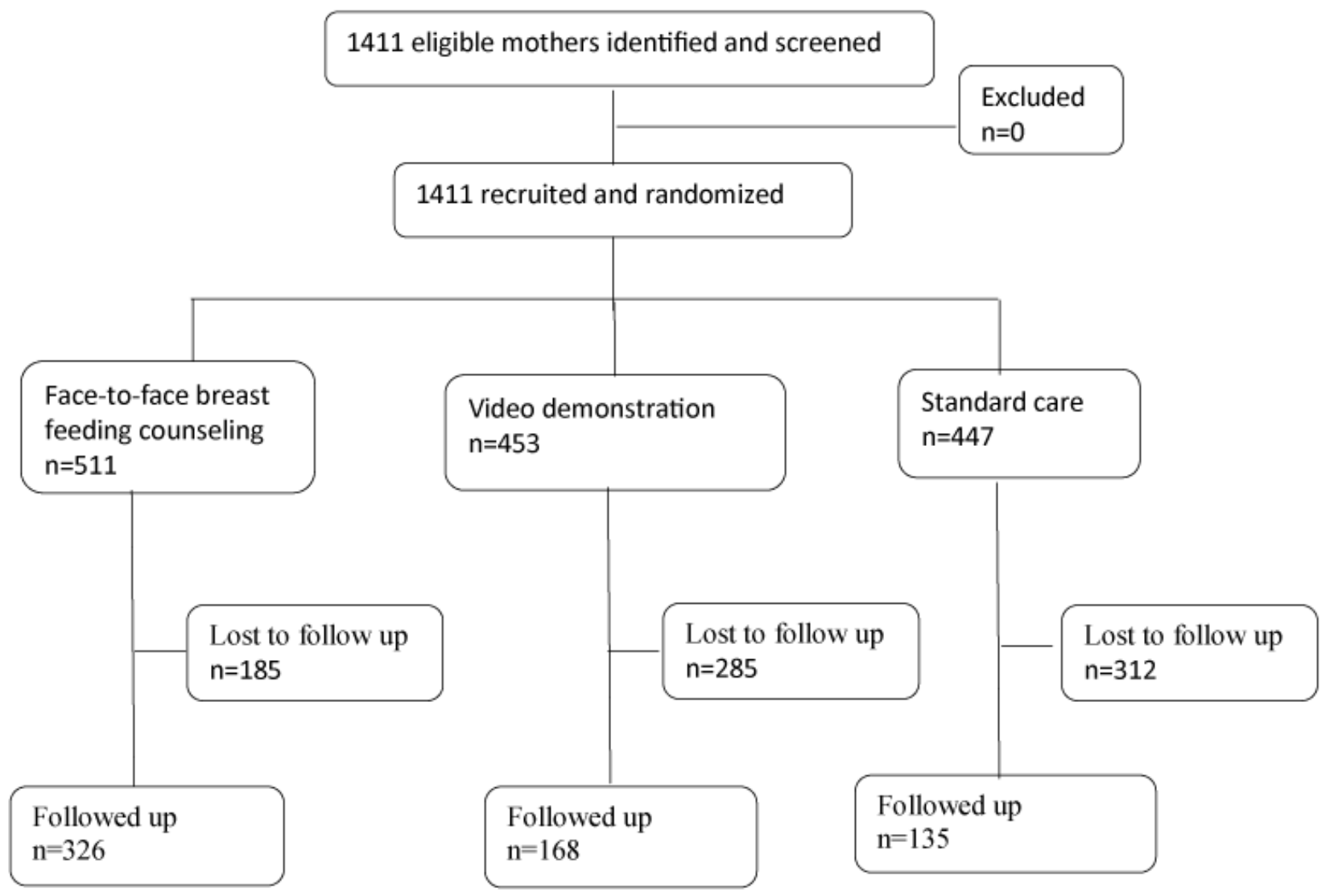

Figure 1: Flow diagram of patient enrollment and follow up

\begin{tabular}{|c|c|c|c|c|c|}
\hline Baseline characteristic & All groups $n=1411$ & $\begin{array}{l}\text { Face-to-face counseling group } \\
\mathrm{n}=511\end{array}$ & Video demonstration group $n=453$ & Control group $n=447$ & $P$ value \\
\hline Gestation (weeks)* & $38.3(1.8)$ & $38.2(1.9)$ & $38.4(1.7)$ & $38.4(1.8)$ & 0.07 \\
\hline Birth weight (grams) * & $2674(426)$ & $2686(427)$ & $2639(436)$ & 2639 (411) & 0.12 \\
\hline Mother's age (years) * & $24.0(3.5)$ & $23.7(3.2)$ & $23.9(3.8)$ & $24.3(3.6)$ & 0.09 \\
\hline Female gender $\mathrm{n}(\%)$ & $677(48 \%)$ & $243(47.6 \%)$ & $215(47.4 \%)$ & $219(49.0 \%)$ & 0.88 \\
\hline Cesarean delivery $\mathrm{n}(\%)$ & $277(19.6 \%)$ & $100(19.5 \%)$ & $98(21.6 \%)$ & $79(17.8 \%)$ & 0.35 \\
\hline Education of mother (years) * & $7.0(4.9)$ & $7.8(4.8)$ & $6.7(5.0)$ & $6.4(4.8)$ & 0 \\
\hline Housewife mother & $1359(96.3 \%)$ & $486(95.2 \%)$ & $437(96.4 \%)$ & $436(97.5 \%)$ & 0.69 \\
\hline Education of father (years) * & $8.7(4.4)$ & $9.3(4.2)$ & $8.3(4.6)$ & $8.3(4.3)$ & 0 \\
\hline Per capita income (rupees) * & $878(668)$ & $853(671)$ & $875(721)$ & $910(606)$ & 0.44 \\
\hline Joint family n (\%) & $1230(87.2 \%)$ & $448(87.6 \%)$ & $413(91.2 \%)$ & $369(82.7 \%)$ & 0 \\
\hline Antenatal checkup n (\%) & $1167(82.7 \%)$ & $405(79.3 \%)$ & $410(90.3 \%)$ & $352(78.7 \%)$ & 0 \\
\hline
\end{tabular}


Page 4 of 5

${ }^{*}$ Data shown as mean (SD)

Table 1: Baseline characteristics

\begin{tabular}{|c|c|c|c|c|c|c|c|c|}
\hline Outcome & $\begin{array}{l}\text { Face-to-face } \\
\text { counseling group } \\
n=326\end{array}$ & $\begin{array}{l}\text { Control } \\
\text { group } n=135\end{array}$ & $\begin{array}{l}\text { Odds ratio } \\
(95 \% \text { Cl)a }\end{array}$ & $P$ value & $\begin{array}{l}\text { Video demonstration } \\
\text { group } n=168\end{array}$ & $\begin{array}{l}\text { Control } \\
\text { group } n=135\end{array}$ & $\begin{array}{l}\text { Odds ratio } \\
(95 \% \text { Cl) a }\end{array}$ & $P$ value \\
\hline Exclusive breast feeding ${ }^{b}$ & $271(83.1 \%)$ & $97(71.8 \%)$ & $\begin{array}{l}1.87 \\
(1.15-3.04)\end{array}$ & 0.01 & $117(69.6 \%)$ & $97(71.8 \%)$ & $\begin{array}{l}0.93 \\
(0.55-1.56)\end{array}$ & 0.67 \\
\hline Hospitalization & $16(4.9 \%)$ & $15(11.1 \%)$ & $\begin{array}{l}0.41 \\
(0.20-0.86)\end{array}$ & 0.02 & $10(6.0 \%)$ & $15(11.1 \%)$ & $\begin{array}{l}0.71 \\
(0.47-1.08)\end{array}$ & 0.11 \\
\hline Weight (grams) ${ }^{a}$ & $4302(926)$ & $4072(872)$ & $\begin{array}{l}230 \text { (-86 to } \\
547)\end{array}$ & 0.15 & $4284(945)$ & $4072(872)$ & $\begin{array}{l}212(-143 \\
\text { to } 567)\end{array}$ & 0.24 \\
\hline Head circumference $(\mathrm{cm})^{\mathrm{a}}$ & $36.8(2.2)$ & $35.6(2.0)$ & $\begin{array}{l}1.2 \text { (0 to } \\
2.5)\end{array}$ & 0.05 & $36.5(2.0)$ & $35.6(2.0)$ & $\begin{array}{l}0.9(-0.3 \text { to } \\
2.2)\end{array}$ & 0.14 \\
\hline \multicolumn{9}{|c|}{ a. Mean difference (standard deviation) for continuous variables } \\
\hline
\end{tabular}

Table 2: Outcomes at six weeks postnatal age

\section{Discussion}

There was an increased rate of exclusive breast feeding at six weeks postnatal age in the group who received face-to-face counseling while video demonstration did not make any difference.

Information on how to feed young infants comes from family beliefs, community practices and information from health workers. Advertising and commercial promotion by food manufacturers is sometimes the source of information for many people, both families and health workers.

Various studies in different parts of the world have shown benefits of lactational counseling and use of audiovisual aids on breast feeding rates [4-7]. Our study is novel as none of the previous studies has compared the effect of video demonstration with face to face counseling.

In a study from Bangladesh, it was observed that repeated organized breast-feeding counselling significantly improved the prevalence of exclusive breast-feeding to $54 \%$ at 5 months postnatal age which was much above the existing national prevalence (12.7\%) [8].

Albernaz et al. reviewed the scientific literature and evaluated studies of face-to-face counseling for the promotion of exclusive breast-feeding [4]. They selected studies describing face-to-face counseling with mothers during only the postnatal period or both the pre- and postnatal periods. Nineteen studies were included. The duration of follow-up, type of intervention performed, and ethnic, socioeconomic, and reproductive characteristics of the groups studied varied widely. Seventeen studies reported a beneficial effect of the intervention, although the magnitude of this effect differed widely across the various studies. Two studies reported a dose-response effect, with the impact being directly proportional to the number of counseling sessions. They concluded that face-to-face counseling, given during different time periods, led to significant changes in the rate of exclusive breast-feeding and the support to the mothers must continue after hospital discharge and must include guidance on breast-feeding techniques and ways to resolve problems that occur.

Anderson et al. assessed the efficacy of peer counseling to promote exclusive breastfeeding among low income inner-city women in Latina community [5]. The likelihood of nonexclusive breastfeeding throughout the first 3 months was significantly higher for the control than the intervention group. They concluded that well-structured, intensive breastfeeding support provided by hospital and communitybased peer counselors is effective in improving exclusive breastfeeding rates among low-income, inner-city women in the United States.

Langer et al. did a randomized clinical trial to see the effects of psychosocial support during labor, delivery and the immediate postpartum period provided by a female companion in a large social security hospital in Mexico City [6]. The frequency of exclusive breastfeeding and behaviors that promote breastfeeding one month after birth were significantly higher in the intervention group. It is important to include psychosocial support as a component of breastfeeding promotion strategies.

Policies to enhance scheduling flexibility and privacy for breastfeeding mothers at work may also be important, given the elevated risk of discontinuation associated with return to work [9].

The possible reasons for increased rates of exclusive breast feeding after face-to-face counseling of mothers are manifold. Counseling motivates the mothers to breast feed their babies and makes them understand the benefits of breast feeding. It addresses their queries and the problems related to breast feeding which if taken care of early after delivery may prevent the use of animal or formula milk. There is a bilateral dialogue between the mother and the counselor and she is free to ask questions and clarify things which she does not understand.

Video demonstration is a unilateral flow of information. The amount of understanding and imbibing the same varies from individual to individual. There is no way for the mother to clarify her 
Citation: Sharma K, Sharma V, Sharma KP (2014) Face to Face Counseling is Associated with Higher Exclusive Breast Feeding Rates at Six Weeks Compared to Audio-Visual Aids: A Randomized Controlled Trial. J Neonatal Biol 3: 137. doi:10.4172/2167-0897.1000137

Page 5 of 5

doubts. There is a possibility that repeated demonstrations may be helpful compared to single time demonstration.

The low exclusive breast feeding rates in joint families might be due to the dominance and interference of other family members especially the mother-in-law. The traditional beliefs and practices of the family are likely to overcome the desire and willingness of the mother to breast feed her baby. Although the mother might have been counseled and willing to breast feed her baby, she might not be able to take the decision and execute the same. Therefore, the family members also need to be counseled for the benefits of exclusive breast feeding and the support they can provide to the mother for the same including providing her with a good nourishing diet and sparing her from the household chores so that she can spend her time with the baby. This family support if taken in the right direction may be converted into a big advantage for exclusive breast feeding.

There was less need for hospitalization among the infants born to mothers in the face-to-face counseling group. This may be because of increased rates of exclusive breast feeding and consequently lesser episodes and severity of illness among these infants.

The limitation of our study is the low follow up rate. The reason may be abstinence from work and migration of some mothers from their parents' house where the delivery took place to their in-laws after the delivery. It is sometimes not feasible for them to follow up at the hospital where they had delivered. This can be improved through home visits for which we did not have the manpower and resources. The follow up rate was better in the face-to-face counseling group compared to the other two groups. This could have been due to the rapport developed by the counselor and the effect of counseling itself. Secondly, the intervention groups received a single session of counseling or video demonstration. It is possible that multiple sessions including antenatal sessions may increase the exclusive breast feeding rates further. Also our study does not discount the possible beneficial effects of visual aids combined with counseling which needs further exploration.
In conclusion, our study shows that face-to-face counseling of mothers was associated with increased rates of exclusive breast feeding and decreased need for hospitalization of infants during the first six weeks of life. There is no effect of video demonstration of a film on breast feeding on the same.

\section{References}

1. Fifty-fourth World Health Assembly (2001) Document A54/INF.DOC./ 4.Global strategy for infant and young child feeding: the optimal duration of exclusive breast-feeding. World Health Organization (WHO), Geneva.

2. Victora CG, Smith PG, Vaughan JP, Nobre LC, Lombardi C, et al. (1987) Evidence for protection by breast-feeding against infant deaths from infectious diseases in Brazil. Lancet 2: 319-322.

3. Der G, Batty GD, Deary IJ (2006) Effect of breast feeding on intelligence in children: prospective study, sibling pairs analysis, and meta-analysis. BMJ 333: 945 .

4. Albernaz E, Victora CG (2003) [Impact of face-to-face counseling on duration of exclusive breast-feeding: a review]. Rev Panam Salud Publica 14: 17-24.

5. Anderson AK, Damio G, Young S, Chapman DJ, Pérez-Escamilla R (2005) A randomized trial assessing the efficacy of peer counseling on exclusive breastfeeding in a predominantly Latina low-income community. Arch Pediatr Adolesc Med 159: 836-841.

6. Langer A, Campero L, Garcia C, Reynoso S (1998) Effects of psychosocial support during labour and childbirth on breastfeeding, medical interventions, and mothers' wellbeing in a Mexican public hospital: a randomised clinical trial. Br J Obstet Gynaecol 105: 1056-1063.

7. Gross SM, Caulfield LE, Bentley ME, Bronner Y, Kessler L, et al. (1998) Counseling and motivational videotapes increase duration of breastfeeding in African-American WIC participants who initiate breastfeeding. J Am Diet Assoc 98: 143-148.

8. Haque MF, Hussain M, Sarkar A, Hoque MM, Ara FA, et al. (2002) Breast-feeding counselling and its effect on the prevalence of exclusive breast-feeding. J Health Popul Nutr 20: 312-316.

9. Taveras EM, Capra AM, Braveman PA, Jensvold NG, Escobar GJ, et al. (2003) Clinician support and psychosocial risk factors associated with breastfeeding discontinuation. Pediatrics 112: 108-115. 